OPEN ACCESS

Edited by: Geoffrey E. Hill, Auburn University, United States

Reviewed by: Barbara Ballentine, Western Carolina University, United States Michael Kopp, Aix-Marseille Université, France

*Correspondence: Marion Petrie marion.petrie@ncl.ac.uk

Specialty section:

This article was submitted to Behavioral and Evolutionary Ecology, a section of the journal Frontiers in Ecology and Evolution

Received: 30 September 2021 Accepted: 30 November 2021 Published: 16 December 2021

Citation:

Petrie M (2021) Evolution by Sexual Selection.

Front. Ecol. Evol. 9:786868. doi: 10.3389/fevo.2021.786868

\section{Evolution by Sexual Selection}

\author{
Marion Petrie* \\ Biosciences Institute, Newcastle University, Newcastle upon Tyne, United Kingdom
}

Charles Darwin published his second book "Sexual selection and the descent of man" in 1871150 years ago, to try to explain, amongst other things, the evolution of the peacock's train, something that he famously thought was problematic for his theory of evolution by natural selection. He proposed that the peacock's train had evolved because females preferred to mate with males with more elaborate trains. This idea was very controversial at the time and it wasn't until 1991 that a manuscript testing Darwin's hypothesis was published. The idea that a character could arise as a result of a female preference is still controversial. Some argue that there is no need to distinguish sexual from natural selection and that natural selection can adequately explain the evolution of extravagant characteristics that are characteristic of sexually selected species. Here, I outline the reasons why I think that this is not the case and that Darwin was right to distinguish sexual selection as a distinct process. I present a simple verbal and mathematical model to expound the view that sexual selection is profoundly different from natural selection because, uniquely, it can simultaneously promote and maintain the genetic variation which fuels evolutionary change. Viewed in this way, sexual selection can help resolve other evolutionary conundrums, such as the evolution of sexual reproduction, that are characterised by having impossibly large costs and no obvious immediate benefits and which have baffled evolutionary biologists for a very long time. If sexual selection does indeed facilitate rapid adaptation to a changing environment as I have outlined, then it is very important that we understand the fundamentals of adaptive mate choice and guard against any disruption to this natural process.

Keywords: natural selection, sexual selection, mate choice, mutation rate, adaptation, rate of evolution

\section{INTRODUCTION}

The reason that Darwin (1859) published a second book after the Origin of Species was revealed in a now famous comment in a letter to Asa Gray in 1860 just a year after the publication of the Origin: "the sight of a Peacock's train whenever I gaze at it makes me sick" (Burkhardt et al., 1993). His crucial insight was that the existence of the peacock's train could not be explained by his theory of evolution by natural selection. Darwin's second book, published in 1871 (Darwin, 1871), outlined 
his theory of evolution by sexual selection. In this book Darwin suggested that the costly peacock's train evolved because females prefer to mate with males that have fancy upper-tail coverts. This book was controversial at the time, and research on sexual selection only really started in earnest in the late 1970s (Hoquet, 2015). Sexual selection is still controversial (Charlesworth, 1988; Clutton-Brock, 2010; Hoquet, 2015), and the aim of this article is to ask whether Darwin was right to distinguish sexual from natural selection. Are the two processes fundamentally different, and, if so, in what way?

\section{WHAT IS THE EVIDENCE FOR FEMALE CHOICE AND WHY DO FEMALES SHOW MATE PREFERENCES?}

Tim Halliday and I provided some of the first evidence testing Darwin's idea (Petrie et al., 1991) in peafowl. The main empirical support for active female choice comes from observations of marked females visiting a lek site. Females always approached more than one male before mating and the male chosen almost invariably had the highest number of eyespots in the train of those visited (see Table 1). Experimental removal of eyespots resulted in a reduction in mating success (Petrie and Halliday, 1994). These results have been replicated by others, although it must be said that not all peafowl researchers are unanimous in their views on the evolution of the peacock's train (Yasmin and Yahya, 1996; Loyau et al., 2005, 2008; Takahashi et al., 2008; Dakin and Montgomerie, 2009, 2011; Harikrishnan et al., 2010).

However, this empirical support instantly raised the question; why do peahens prefer to mate with peacocks with fancy trains? Theories of female choice have proliferated but, broadly, females could either gain direct benefits from their choice, where males provide resources that directly help females successfully reproduce, or indirect genetic benefits (Kirkpatrick and Ryan, 1991), where mating with a particular displaying male results in higher offspring fitness. Female choice is a characteristic like any other, and to have evolved the benefits of choosing between males must outweigh the costs. In peafowl, there is a prima facie case for indirect genetic benefits or "good genes" driving the mating preferences of peahens, since peacocks classically provide no resources other than seminal fluid to aid female reproduction. They do not fertilise more eggs per female (Birkhead and Petrie, 1995), they do not courtship feed, they do not defend females from other males, they just stand displaying on the same small spot looking beautiful, and females are free to move between males (Petrie et al., 1991; Harikrishnan et al., 2010). This has led some to suggest that peahens incur few costs when choosing between males on leks and there is no need to evoke any benefits to mate choice; female choice is arbitrary and has no utilitarian function (Hoquet, 2015). However, this thinking ignores the fact that there is a huge inherent cost associated with choosing to mate with a displaying male that provides no paternal care for offspring (Petrie and Lipsitch, 1994). Moreover, given that there is marked variation in male mating success on peacock leks with most males achieving no copulations at all, it is very hard to
TABLE 1 | Males visited by marked individual peahens.

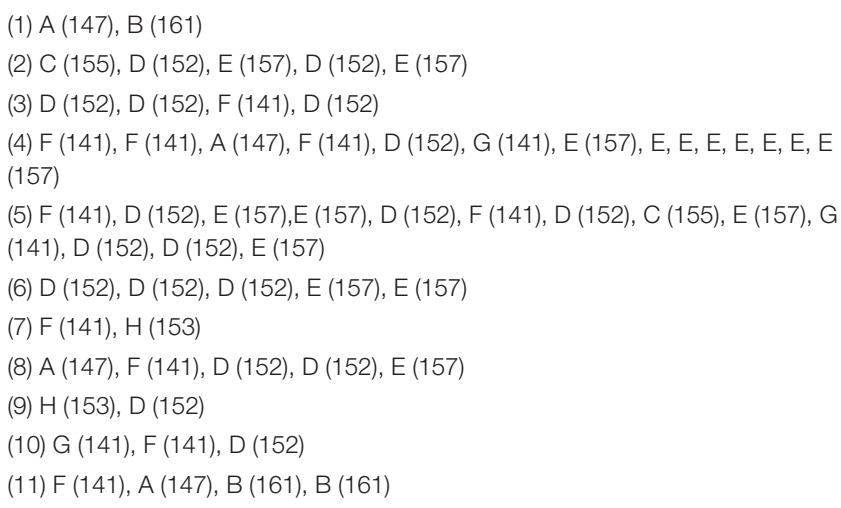

The above was originally published in Animal Behaviour in 1991. It shows the movements of 11 marked females between males on one lek site (flint pit paddock) at Whipsnade from the time that they first visited males (A-H) until they mated with the last male visited. The numbers in brackets are the numbers of eyespots in the trains of the males visited. For example, female 2 visited three different males before mating with the male $E$. These data provide clear evidence of active female choice. Peahens always visit more than one male before mating and, in 10 out of 11 cases, females finally mated with the male with the highest eye-spot number of those visited (best-of-n). This is good evidence that eye-spot number or something closely related to it is important for female choice. Alan Grafen kindly analysed these data to take account of the fact that several of the males appeared more than once in the choice sets but, he concluded that it was very unlikely that this result could have occurred by chance. Other models were tested, and Alan found that the only other model that could potentially explain the pattern was that the female mated with the male that had more eyespots than the last one visited. However, this condition is satisfied earlier on in many of the choice sets and he concluded that the best-of- $n$ model provided the best fit to the data. See Petrie et al. (1991) for further details.

understand how such a system could be evolutionarily stable for both males and females.

\section{WHY DO FEMALES PREFER TO MATE WITH DISPLAYING MALES THAT PROVIDE NO PATERNAL CARE?}

In 1994, using a game theoretical modelling approach, Mark Lipsitch and I considered why a mutant gene for caring does not invade a population of displaying males. Surely a mutation for caring which arose in an unsuccessful displaying male would spread through a population as females could increase their reproductive success with male help (Petrie and Lipsitch, 1994). We showed that the invasion and stability conditions for female choice for displaying males are satisfied only if the benefits of choice are greater than the cost of lost male care. If females are only gaining indirect genetic benefits, then these conditions are satisfied only when the amount of variation among males in genetic quality is large. However, this raises yet another serious problem for evolutionary theory as Fisher's fundamental theorem states that there is always diminishing heritable variation in fitness-related traits, because strong directional selection would quickly remove any genetic variation (Fisher, 1930). Female choice for "good genes" can only evolve and be maintained if there are genetic quality differences between males. The main problem therefore is that even if males varied in genetic quality, 
strong directional selection would quickly remove it and all males should then be of similarly high quality. This is sometimes known as the lek paradox (Pomiankowski and Møller, 1995). There are a number of theories that have been proposed to explain the lek paradox and the most commonly cited is that there is variation in condition dependent traits which could potentially reflect variation in a large number of genes (Kotiaho et al., 2008).

\section{COULD MUTATION PROVIDE THE GENETIC VARIATION REQUIRED TO MAINTAIN COSTLY FEMALE CHOICE?}

Mutation is the ultimate source of all genetic variation, so could mutation provide the genetic variation required to maintain costly female choice? Mutations are mainly harmful, for every beneficial mutation with an increase in fitness there are very many more deleterious mutations which reduce fitness and some lethal mutations, so it is thought that natural selection will always act to keep the mutation rate as low as possible (Eyre-Walker and Keightley, 2007). And it is true that several DNA repair mechanisms have evolved to ensure fidelity in DNA replication.

The main problem of how genetic variation is maintained in the peacock's train is even more acute when the empirical evidence from peafowl is considered. Not only do fancy peacocks have higher mating success (Petrie et al., 1991; Petrie and Halliday, 1994), they also have higher survivorship (Petrie, 1992; Jennions et al., 2001), their offspring survive better (Petrie, 1994; Hale et al., 2009), and females lay more eggs for males with fancy trains (Petrie and Williams, 1993; Loyau et al., 2007), so strong directional selection would remove any variation pretty quickly. But, observably it doesn't (see photo Figure 1) and if one looks at the coefficient of additive genetic variance in sexually selected traits, we find that, in general, there is more and not less genetic variation in sexually selected characteristics (Pomiankowski and Møller, 1995; Pike et al., 2009). This fact alone demands a different sort of explanation where sexual selection promotes rather than depletes genetic variation.

So how could sexual selection promote genetic variation? In 1997, Tadeii et al. published a manuscript in Nature which described the action of a mutator gene, one that could control the rate of mutation, basically, a mutated DNA repair gene (Taddei et al., 1997). They argued that if an elevated mutation rate became associated with a beneficial mutation it could hitch-hike into a population and that this association could provide a continual source of genetic variation. However, the authors concluded that this would only be likely to be important in asexual prokaryotes because the recombination that occurs in sexually reproducing eukaryotes would quickly disrupt the genetic hitch-hiking and the mutated gene would be selected against (Taddei et al., 1997). It occurred to me that whilst this may be true in situations without sexual selection, if there is an element of female choice for males with beneficial mutations and rejection of any males with deleterious mutations, so that the level of fitness is revealed in some way by the degree of train elaboration, then maybe a higher mutation rate could be sustained in a sexually reproducing species (Petrie and Roberts, 2007).

\section{CAN SEXUAL SELECTION MAINTAIN A HIGHER MUTATION RATE?}

I visited Geoff Parker in Liverpool in 1997 to discuss this possibility and, although he had some doubts, he broadly thought it was an interesting idea and suggested I submitted a note to Nature. Unfortunately, it did not pass muster with the referees who were not convinced by a simple verbal model, and it took a further 10 years before the manuscript was finally published. Using a simulation modelling approach conducted by Gilbert Roberts, we showed that female choice of a male with higher fitness (higher offspring survival and mating success) was sufficient to raise the rate of mutation in a population of displaying males when compared to that sustained in a population where mating occurred at random (Petrie and Roberts, 2007). Moreover, female choice selecting the fittest of just two males was sufficient to double the rate of mutation over that seen under random mating. This process provides a selfsustaining solution to the lek paradox, as the more males females choose between, the higher the relative male fitness a female gains and, the greater mutation rate that can be sustained.

The greater the mutation rate sustained, the more it pays to choose between males and so on, thus resulting in a positive feedback loop between the level of genetic variation in the population and the level of female choice (Petrie and Roberts, 2007).

This idea is testable, and a few recent manuscripts have attempted to do this, the main predictions of the hypothesis are: -

1) Interspecific variation in the level of sexual selection will be positively related to genetic variability (Petrie et al., 1998).

2) There should be a higher mutation rate in species with more intense sexual selection (Møller and Cuervo, 2003; Ellegren, 2006; Anmarkrud et al., 2011; Baur and Berger, 2020).

3) Mutation rates should be higher in sexual as opposed to non-sexual traits (Møller and Cuervo, 2003).

4) There should be a higher rate of evolutionary change in sexually selected lineages (Lumley et al., 2015; IglesiasCarrasco et al., 2019).

Of course, the actual tests of these predictions depend on the measures of both the degree of sexual selection and the genetic mechanism that controls the rate of mutation. Whilst I originally imagined a mutator gene as the disruption of a DNA repair gene there are several other possible mechanisms that can give rise to adaptive variation, such as that accompanying transposable elements or loss of function genes (Lynch et al., 2016; Charlesworth et al., 2017; Murray, 2020). Moreover, the different mechanisms are not necessarily always inevitably affected by recombination. There is now evidence for recombination low spots in the genome for example, classically there is very little recombination at the MHC (Nachman, 2002). There is also evidence for mutational hot spots, so any mechanism for generating mutation does not necessarily affect the whole genome (Lynch et al., 2016). Next generation sequencing opens up many possibilities for testing the idea at the genomic level. Hopefully, it 


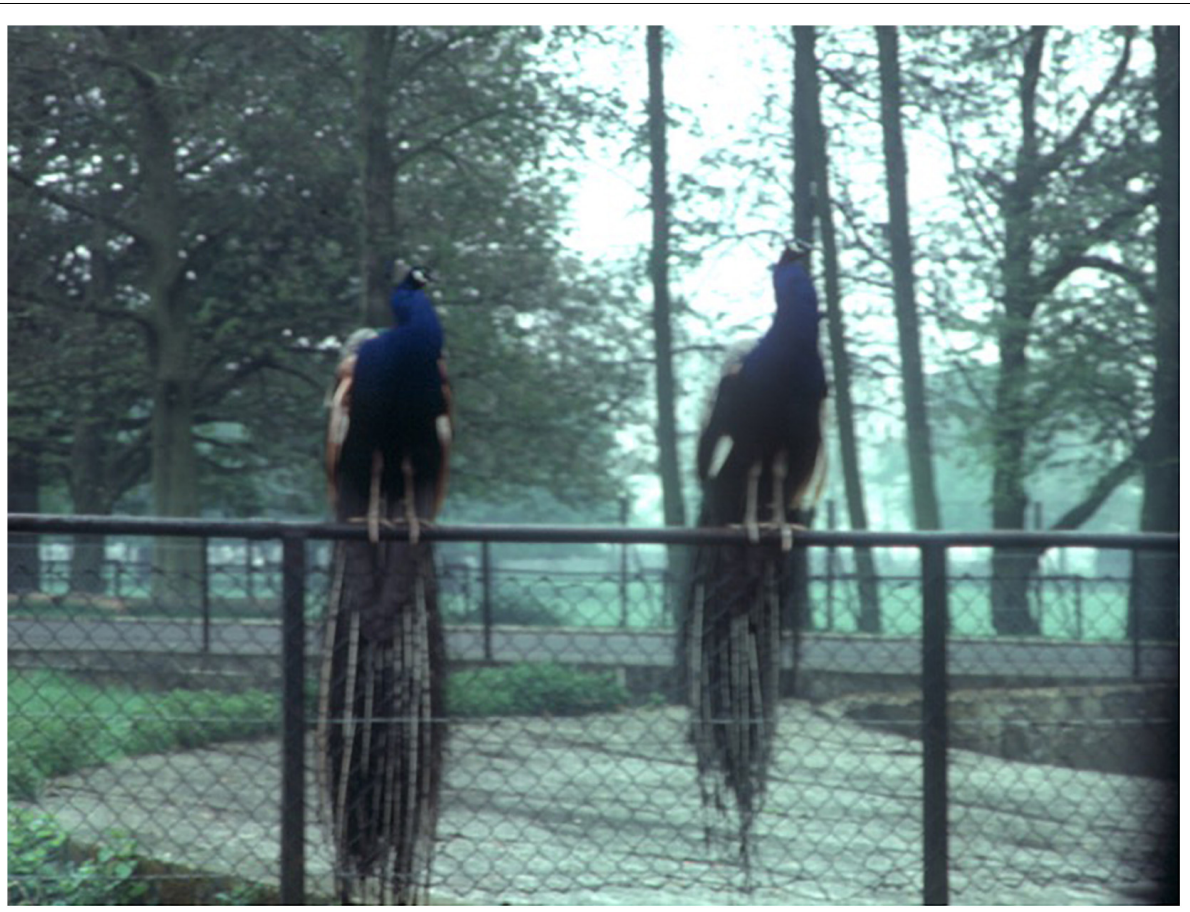

FIGURE 1 | Photograph of two unmarked lek males sitting side-by-side on a fence at Whipsnade. The photograph whilst of quite poor quality clearly shows that there is marked variation in both the length and breadth (number of feathers) in the male's trains (copyright M. Petrie).

will be possible to identify and distinguish the different signatures of sexual and natural selection.

I believe Evolution by sexual selection to be a fundamentally different process to Evolution by natural selection and that Darwin was right to distinguish the two processes. John Maynard Smith, who was my personal tutor when I was an undergraduate at Sussex University from 1972 to 1975, said amongst many other sensible things, "that if you can't write it on the back of a matchbox you haven't understood it". So, I'm now going to summarise what I think I have said mathematically, which illustrates what I believe to be the main fundamental difference between natural and sexual selection.

Under natural selection the rate of evolutionary change $\left(E_{n}\right)$ in a phenotypic character is proportional to the amount of genetic variation among individuals in a population in that character, the additive genetic variance $\left(\mathrm{V}_{\mathrm{A}}\right)$ and the strength of natural selection $\left(S_{n}\right)$. Where the strength of selection $\left(S_{n}\right)$ is the relative increase in the number of offspring surviving to reproduction with that character.

$$
\mathrm{E}_{\mathrm{n}} \propto \mathrm{V}_{\mathrm{A}} \times \mathrm{S}_{\mathrm{n}}
$$

Under sexual selection the rate of evolutionary change in a character $\left(E_{\mathrm{S}}\right)$ is also proportional to $\mathrm{V}_{\mathrm{A}}$ and the strength of selection. However, the strength of sexual selection is proportional to the relative increase in the number of offspring surviving to reproduction $\left(S_{n}\right)$ and the relative number of mates a male $\left(\mathrm{N}_{\mathrm{m}}\right)$ with that character obtains, since the number of gene copies in the next generation is also dependent upon relative mating success.

$$
\mathrm{E}_{\mathrm{s}} \propto \mathrm{V}_{\mathrm{A}} \times \mathrm{S}_{\mathrm{n}} \mathrm{N}_{\mathrm{m}}
$$

However, under sexual selection the amount of genetic variation is also proportional to the strength of selection on the rate of mutation $(\mu)$

$$
\mathrm{V}_{\mathrm{A}} \propto \mu \times \mathrm{S}_{\mathrm{n}} \mathrm{N}_{\mathrm{m}} .
$$

So, under Sexual selection and, substituting 3 in 2, gives,

$$
\mathrm{E}_{\mathrm{s}} \propto \mu \times\left(\mathrm{S}_{\mathrm{n}} \mathrm{N}_{\mathrm{m}}\right)^{2} .
$$

The rate of evolutionary change is therefore much greater under sexual selection, where the strength of selection is potentially magnified by mating success and where sexual selection can promote the rate of mutation. These are, in my opinion, the fundamental differences between natural selection and sexual selection which warrant Darwin's decision to treat the two processes separately.

\section{DISCUSSION}

Sexual selection is a much more powerful evolutionary force than natural selection because variation in mating success can magnify selection and simultaneously promote and maintain novel genetic variation among individuals, which ultimately fuels rapid evolutionary change.

Interestingly, if an unsuccessful male on a peacock lek with lower-than-average fitness (as a result of deleterious mutations) 
gains no mates at all (normally the majority of males on a lek), then the net rate of evolutionary change on a phenotypic character is zero. Only when the relative fitness of a male is greater-than-average (as a result of a beneficial mutation) will selection result in rapid adaptive change since only these males will gain mates. An increase in the rate of mutation via a mutator gene will therefore also only occur if the mutator gene is linked to a beneficial mutation which can hitch-hike into the population. The self-sustaining positive-feedback loop in the level of additive genetic variance that results from this process maintains the female preference for males that do nothing but show-off their good genes.

I don't think that the precise form of the mate preference function used in the model is important. Females do need to choose males and unless there are genetic differences between males there is no basis for female choice. A non-linear preference function as well as a linear preference function in relation to male quality would in my opinion produce the same qualitative result. The number of mates obtained by any one male, however, will quantitatively affect the strength of selection for the genetic characteristics of that male.

Although the natural history underlying the model is based on inter-sexual selection or mate choice for males (epitomised by the lek mating system of peafowl) with a character that reveals their underlying genetic quality, there is no reason to believe that the fundamentals of this process cannot also be applied to intra-sexual selection, where the outcome of contests between individuals of the same sex determines mating success. Wherever there is variance in mating success which is ultimately determined by variation in genetic quality then there is the opportunity for very rapid evolutionary change.

Sexual selection when viewed in this way has the potential to explain other evolutionary problems (Sheratt and Wilkinson, 2009) that are characterised by having impossibly large costs and no obvious immediate benefits and that have baffled evolutionary biologists for a long time, such as the evolution of sexual reproduction and the existence of males (Smith, 1986; Agrawal, 2001; Siller, 2001; Whitlock and Agrawal, 2009; Roberts and Petrie, 2021). The problem with the evolution of sexual reproduction can be briefly summed up as the cost of producing males. The number of offspring produced by an asexual female is twice that produced by a sexual female (producing equal numbers of male and female offspring) since males cannot produce offspring by themselves. In order to overcome this large numerical cost a sexually produced offspring must be twice as fit as an asexually produced offspring.

Only if there are genetic differences between males in a population will it pay females to outbreed in order to exchange their male genes to increase the genetic quality of their offspring. Both Agrawal (2001) and Siller (2001), modelled the effect of sexual selection on the production of males and, concluded that the function of males in a sexually reproducing population was to remove bad genes or reduce the genetic load of a population (Whitlock and Agrawal, 2009). If sexual selection functions in the way I have described above, then sexual selection for good genes will provide a short-term advantage to produce males and rapidly facilitate the evolution of sexual reproduction (Roberts and Petrie, 2021).
If sexual selection does facilitate rapid adaptation to a changing environment then it is very important that we understand the fundamentals of adaptive mate choice and guard against any disruption to this process. This is especially true when thinking about the conservation of species facing rapid climate change (Gosling and Sutherland, 2000) or adaptation to the emergence of new zoonotic diseases (Zuk, 2002) such as Covid-19.

Any process that interferes with a female's ability to discriminate between potential mates is a threat to the fitness of a population. The prevention of adaptive female choice in humans can be imposed politically or by religious doctrine and this can and does occur in human populations. Arranged marriages, forced matings and excessive control of female behaviour in societies can result in sub-optimal, maladaptive matings which in turn can adversely influence offspring health. The concomitant effect of these practices or of any environmental pollutants such as artificial chemicals and drugs on adaptive mate choice behaviour, is not routinely considered and, given the importance of gaining good genes for offspring survival to reproduction in all species, it strikes me that this is a major oversight.

We live in a rapidly changing world, I would argue that it is now imperative that in 2021, the 150th anniversary of the publication of Darwin's theory of evolution by sexual selection (1871), we finally accept that sexual selection is a major force in adaptation and evolutionary change and needs to be taken much more seriously.

\section{DATA AVAILABILITY STATEMENT}

The original contributions presented in the study are included in the article/supplementary material, further inquiries can be directed to the corresponding author.

\section{AUTHOR CONTRIBUTIONS}

The author confirms being the sole contributor of this work and has approved it for publication.

\section{ACKNOWLEDGMENTS}

Many people have contributed to my scientific ideas, but I am particularly grateful to the inspirational John Maynard Smith*, who taught me how to think about evolution and introduced me to the problem of sex. I would also like to acknowledge the influence of my family, Morris Gosling, Emma Gosling, and Chloe Conces (nee Gosling) who all have discussed sexual selection with me and provided unfailing encouragement and support throughout my career. I am particularly grateful to the following friends, colleagues and coworkers who I have had formative discussions with including Rauno Alatalo*, Malte Andersson, Clive Catchpole, Tim CluttonBrock, Richard Dawkins, Corry Gellatly, Patty Gowaty, Alan 
Grafen, Tim Halliday*, Mark Hauber, Marie Hale, Bill Hamilton*, Nigella Hillgarth, Sarah Blaffer Hrdy, Richy Hetherington, Mike Jennions, Mark Kirkpatrick, Tom Kirkwood, John Krebs, Phyllis Lee, Jan Lifjeld, Mark Lipsitch, Angela McLean, Anders Pape Møller, Geoff Parker, Ian Owens, Andrew Pomiankowski, Tom Pike, S. Craig Roberts, Gilbert Roberts, Matt Ridley, Gunilla Rosenqvist, Dafila Scott, Diana Singer, Bill Sutherland, Quinton Spratt, Tamas Szekely, Bob Trivers, and Kirsten Wolff. *These

\section{REFERENCES}

Agrawal, A. F. (2001). Sexual selection and the maintenance of sexual reproduction. Nature 411, 692-695. doi: 10.1038/35079590

Anmarkrud, J. A., Kleven, O., Augustin, J., Bentz, K. H., Blomqvist, D., Fernie, K. J., et al. (2011). Factors affecting germline mutations in a hypervariable microsatellite: a comparative analysis of six species of swallows (Aves: Hirundinidae). Mutat. Res. 708, 37-43. doi: 10.1016/j.mrfmmm.2011.01.006

Baur, J., and Berger, D. (2020). Experimental evidence for effects of sexual selection on condition-dependent mutation rates. Nat. Ecol. Evol. 4, 737-744. doi: 10. 1038/s41559-020-1140-7

Birkhead, T. R., and Petrie, M. (1995). Ejaculate features and sperm utilisation in the peafowl Pavo cristatus. Proc. R. Soc. Lond. B. 261, 153-158.

Burkhardt, F., Porter, D. M., Browne, J., and Richmond, M (eds) (1993). The correspondence of Charles Darwin, Vol. 8. Cambridge: Cambridge University Press.

Charlesworth, B. (1988). The evolution of mate choice in a Fluctuating Environment. J. Theor. Biol. 130, 191-204. doi: 10.1016/s0022-5193(88)80 094-8

Charlesworth, D., Barton, N. H., and Charlesworth, B. (2017). The sources of adaptive variation. Proc. R. Soc. B 284:20162864.

Clutton-Brock, T. (2010). We do not need a Sexual Selection 2.0-nor a theory of Genial Selection. Anim. Behav. 79, e7-e10.

Dakin, R., and Montgomerie, R. (2009). Peacocks orient their courtship displays towards the sun. Behav. Ecol. Sociobiol. 63, 825-834. doi: 10.1007/s00265-0090717-6

Dakin, R., and Montgomerie, R. (2011). Peahens prefer peacocks displaying more eyespots, but rarely. Anim. Behav. 82, 21-28. doi: 10.1016/j.anbehav.2011.03. 016

Darwin, C. (1871). The Descent of Man, and Selection in Relation to Sex. London: John Murray.

Darwin, C. R. (1859). The Origin of Species. London: John Murray.

Ellegren, H. (2006). Characteristics, causes and evolutionary consequences of male-biased mutation. Proc. Biol. Sci. 274, 1-10. doi: 10.1098/rspb.2006.3720

Eyre-Walker, A., and Keightley, P. (2007). The distribution of fitness effects of new mutations. Nat. Rev. Genet. 8, 610-618.

Fisher, R. A. (1930). The Genetical Theory of Natural Selection. Oxford: Clarendon Press.

Gosling, L. M., and Sutherland, W.J. (Eds) (2000). Behaviour and Conservation. Cambridge: Cambridge University Press, 479.

Hale, M. L., Verduijn, M. H., Møller, A. P., Wolff, K., and Petrie, M. (2009). Is the peacock's train an honest signal of genetic quality at the Major Histocompatibility Complex? J. Evol. Biol. 22, 1284-1294. doi: 10.1111/j.14209101.2009.01746.x

Harikrishnan, S., Vasudevan, K., and Sivakumar, K. (2010). Behavior 286 of Indian peafowl Pavo cristatus Linn. 1758 during the mating period in a natural population. Open Ornithol. J. 3, 13-19.

Hoquet, T. (Ed) (2015). Current Perspectives on Sexual Selection What's Left After Darwin?. Berlin: Springer.

Iglesias-Carrasco, M., Jennions, M. D., Ho, S. Y. W., and Duchene, D. A. (2019). Sexual selection, body mass and molecular evolution interact to predict diversification in birds. Proc. R. Soc. B 286:20190172. doi: 10.1098/rspb.2019. 0172

Jennions, M. D., Møller, A. P., and Petrie, M. (2001). The relationship between sexual attractiveness and adult survivorship: a meta-analysis. Q. Rev. Biol. 76, 3-36. scientists are sadly no longer with us but they are forever in my thoughts. I am grateful to the Zoological Society of London for allowing me to work at Whipsnade Park and to Quinton Spratt for allowing me to work on his farm in Norfolk and to the NERC, DARPA, and the Wellcome Trust for financial support for the empirical work reported here. Lastly, I would like to thank the editor and reviewers whose comments have improved the original version of this manuscript.

Kirkpatrick, M., and Ryan, M. J. (1991). The evolution of mating preferences and the paradox of the lek. Nature 350, 33-38. doi: 10.1038/350033a0

Kotiaho, J. S., LeBas, N. R., Puurtinen, M., and Tomkins, J. L. (2008). On the resolution of the lek paradox. Trends Ecol. Evol. 23, 1-3.

Loyau, A., Petrie, M., Saint Jalme, M., and Sorci, G. (2008). Do peahens not prefer peacocks with more elaborate trains? Anim. Behav. 76, e5-e9.

Loyau, A., Saint Jalme, M., and Sorci, G. (2005). Intra and inter-sexual selection for multiple traits in the peacock (Pavo cristatus). Ethology 111, 810-820. doi: 10.1111/j.1439-0310.2005.01091.x

Loyau, A., Saint Jalme, M., Mauget, R., and Sorci, G. (2007). Male sexual attractiveness affects the investment of maternal resources into the eggs in peafowl (Pavo cristatus). Behav. Ecol. Sociobiol. 61, 1043-1052. doi: 10.1007/ s00265-006-0337-3

Lumley, A. J., Michalczyk, L., Kitson, J. J. N., Spurgin, L. G., Morrison, C. A., Godwin, G. L., et al. (2015). Sexual selection protects against extinction. 356. Nature 522, 470-473. doi: 10.1038/s41586-018-0020-7

Lynch, M., Ackerman, M. S., Gout, J. F., Long, H., Sung, W., Thomas, W. K., et al. (2016). Genetic drift, selection and the evolution of the mutation rate. Nat. Rev. Genet. 17, 704-714. doi: 10.1038/nrg.2016.104

Møller, A. P., and Cuervo, J. J. (2003). Sexual selection, germline mutation rate and sperm competition. BMC Evol. Biol. 3:6. doi: 10.1186/1471-2148-3-6

Murray, A. W. (2020). Can gene-inactivating mutations lead to evolutionary novelty? Curr. Biol. 30, R465-R471. doi: 10.1016/j.cub.2020.03.072

Nachman, M. W. (2002). Variation in recombination rate across the genome: evidence and implications. Curr. Opin. Genet. Dev. 12, 657-663. doi: 10.1016/ s0959-437x(02)00358-1

Petrie, M. (1992). Peacocks with low mating success are more likely to suffer predation. Anim. Behav. 44, 585-586.

Petrie, M. (1994). Improved growth and Survival of offspring of peacocks with more elaborate trains. Nature 371, 598-599. doi: 10.1038/371598a0

Petrie, M., and Halliday, T. (1994). Experimental and natural changes in the peacock's (Pavo cristatus) train can affect mating success. Behav. Ecol. Sociobiol. 35, 213-217.

Petrie, M., and Lipsitch, M. (1994). Avian polygyny is most likely in populations with high variability in heritable male fitness. Proc. R. Soc. Lond. B. 256, 275-280.

Petrie, M., and Roberts, G. (2007). Sexual selection and the evolution of evolvability. Heredity 98, 198-205. doi: 10.1038/sj.hdy.6800921

Petrie, M., and Williams, A. (1993). Peahens lay more eggs for peacocks with larger trains. Proc. R. Soc. Lond. B. 251, 127-131. doi: 10.1111/j.1420-9101.2009.01 746.x

Petrie, M., Doums, C., and Møller, A. P. (1998). The degree of extra-pair paternity increases with genetic variability. Proc. Natl. Acad. Sci. U.S.A. 95, 9390-9395. doi: 10.1073/pnas.95.16.9390

Petrie, M., Halliday, T. R., and Sanders, C. (1991). Peahens prefer peacocks with elaborate trains. Anim. Behav. 41, 323-331.

Pike, T. W., Cotgreave, P., and Petrie, M. (2009). Variation in the peacock's train shows a genetic component. Genetica 135, 7-11. doi: 10.1007/s10709-0079211-0

Pomiankowski, A., and Møller, A. P. (1995). A resolution of the lek paradox. Proc. R. Soc. Lond. Ser. B 260, 21-29. doi: 10.1098/rspb.1995.0054

Roberts, G., and Petrie, M. (2021). Sexual selection for males with beneficial mutations. BioRxiv [Preprint] doi: 10.1101/2021.05.25.44 5661

Sheratt, T. N., and Wilkinson, D. M. (2009). Big Questions in Ecology and Evolution. Oxford: University Press, Oxford. 
Siller, S. (2001). Sexual selection and the maintenance of sex. Nature 411, 689-692. doi: $10.1038 / 35079578$

Smith, J. M. (1986). Contemplating life without sex. Nature 324, 300-301.

Taddei, F., Radman, M., Maynard-Smith, J., Toupance, B., Gouyon, P. H., and Godelle, B. (1997). Role of mutator alleles in adaptive evolution. Nature 387, 700-702. doi: $10.1038 / 42696$

Takahashi, M., Arita, H., Hiraiwa-Hasegawa, M., and Hasegawa, T. (2008). Peahens do not prefer peacocks with more elaborate trains. Anim. Behav. 75, 1209-1219. doi: 10.1016/j.anbehav.2007.10.004

Whitlock, M. C., and Agrawal, A. F. (2009). Purging the genome with sexual selection: reducing mutation load through selection on males. Evolution 63 , 569-582. doi: 10.1111/j.1558-5646.2008.00558.x

Yasmin, S., and Yahya, H. S. A. (1996). Correlates of mating success in Indian peafowl. Auk 113, 490-492.

Zuk, M. (2002). Sexual Selections What we Can and Can't Learn About Sex from Animals. Berkeley, CA: University of California Press.
Conflict of Interest: The author declares that the research was conducted in the absence of any commercial or financial relationships that could be construed as a potential conflict of interest.

Publisher's Note: All claims expressed in this article are solely those of the authors and do not necessarily represent those of their affiliated organizations, or those of the publisher, the editors and the reviewers. Any product that may be evaluated in this article, or claim that may be made by its manufacturer, is not guaranteed or endorsed by the publisher.

Copyright $(02021$ Petrie. This is an open-access article distributed under the terms of the Creative Commons Attribution License (CC BY). The use, distribution or reproduction in other forums is permitted, provided the original author(s) and the copyright owner(s) are credited and that the original publication in this journal is cited, in accordance with accepted academic practice. No use, distribution or reproduction is permitted which does not comply with these terms. 